\title{
pnmbalina
}

(8)

\section{El ciclo troyano y las pircas diaguitas en Silencio de Piedra de Guillermo Montilla Santillán}
Autor(es): $\quad$ Pégolo, Liliana; Meardi, Florencia; Ramírez, Ramírez; Romero, Ulises
Publicado por: Centro de Estudos Clássicos e Humanísticos da Universidade de
URL persistente:
Coimbra; Imprensa da Universidade de Coimbra
DOI:
URI:http://hdl.handle.net/10316.2/30268
DOI:http://dx.doi.org/10.14195/978-989-721-038-9_42

Accessed : $\quad$ 26-Apr-2023 14:55:27

A navegação consulta e descarregamento dos títulos inseridos nas Bibliotecas Digitais UC Digitalis, UC Pombalina e UC Impactum, pressupõem a aceitação plena e sem reservas dos Termos e Condições de Uso destas Bibliotecas Digitais, disponíveis em https://digitalis.uc.pt/pt-pt/termos.

Conforme exposto nos referidos Termos e Condições de Uso, o descarregamento de títulos de acesso restrito requer uma licença válida de autorização devendo o utilizador aceder ao(s) documento(s) a partir de um endereço de IP da instituição detentora da supramencionada licença.

Ao utilizador é apenas permitido o descarregamento para uso pessoal, pelo que o emprego do(s) título(s) descarregado(s) para outro fim, designadamente comercial, carece de autorização do respetivo autor ou editor da obra.

Na medida em que todas as obras da UC Digitalis se encontram protegidas pelo Código do Direito de Autor e Direitos Conexos e demais legislação aplicável, toda a cópia, parcial ou total, deste documento, nos casos em que é legalmente admitida, deverá conter ou fazer-se acompanhar por este aviso.

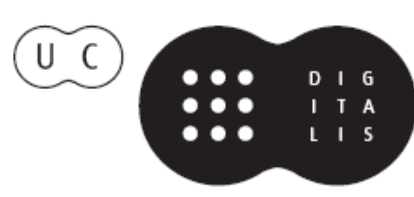




\section{De ayer a hoy}

\section{Influencias clásicas en la literatura}

\section{Aurora López, Andrés Pociña, Maria de Fátima Silva (coords.)}




\title{
El CiClo troyano y las Pircas diaguitas en SILENCIO DE PIEDRA De Guillermo Montilla Santillán
}

\author{
Liliana Pégolo, Florencia Meardi, Cristian Ramírez, Ulises Romero \\ Universidad de Buenos Aires - UBACyT
}

De manera semejante a El jardin de piedra, el tucumano Guillermo Montilla Santillán se apropia del mito clásico a fin de producir un texto donde el relato legendario es funcional a una teatralidad contemporánea y provincial, ambientada en el noroeste argentino. En Silencio de piedra, Montilla Santillán recurre al motivo de la ciudad asediada y a la mujer robada, enamorada de su raptor, para exponer el destino de quienes defienden su territorio frente a los designios de los poderosos. Así Héctor, Casandra y Aquiles, Helena y Paris, entre otros personajes de la tradición históricoliteraria nacional, vuelven a protagonizar el relato, en torno a las pircas diaguitas, mientras se debaten por el dominio de una mina a cielo abierto. Las relaciones entre los textos están establecidas desde el comienzo y será el propósito de esta comunicación analizar los intersticios intertextuales que se producen entre la trama mítica y su representación contemporánea, para comprobar que el mito sacraliza el espacio dramático, transformándose en textualidad simbólica.

Una vez más, de manera semejante a lo textualizado en El jardín de piedra, donde en el ingenio zafrero conviven monstruos locales como "el Familiar" y helénicos como el Minotauro, el dramaturgo tucumano, Guillermo Montilla Santillán, se apropia del mito clásico, en particular del ciclo troyano, para producir un texto en el cual el relato legendario es funcional a una teatralidad contemporánea y provincial, ambientada en el noroeste argentino.

En Silencio de piedra ${ }^{1}$, Montilla Santillán recurre al motivo de la ciudad asediada por enemigos superiores en fuerzas y recursos, y a la mujer robada enamorada de su raptor, evocadores ambos de la narración homérica de la mítica Troya, para exponer el destino de quienes defienden su territorio frente a los designios inexpugnables de los poderosos. Así es que Héctor, Casandra y Aquiles, Helena y Paris, entre otros personajes pertenecientes a la tradición histórico-literaria nacional como Facundo, vuelven a ser protagonistas del relato, en este caso, en torno a las pircas diaguitas, mientras los bandos se debaten por el dominio de una mina a cielo abierto.

Como ocurre en otras producciones de Montilla Santillán el mito se encuentra en el sustrato del texto emergente operando como inspirador

\footnotetext{
${ }^{1}$ La obra está fechada por el autor el 11 de febrero del año 2009.
} 
de una textualidad dramática innovadora, que combina las preocupaciones ecológicas y la denuncia del intervencionismo de poderes económicos trasnacionales con las estructuras del relato legendario, que iluminan el conflicto desde una perspectiva simbólico-alegórica. A la lectura en clave de los motivos argumentales debe sumarse la impronta folclórica de los elementos constitutivos del lenguaje dramático en el que se incluye la copla popular, mixturando la prosa y el verso junto a la solemnidad críptica del discurso profético.

Como afirma Jorge Dubatti en Concepciones de teatro. Poéticas teatrales y bases epistemologías (Buenos Aires,2009), las producciones literarias que entremezclan universos en apariencia disímiles "suelen ser espacios de heterogeneidad, tensión, debate, cruce, hibridez de diferentes materiales y procedimientos, espacio de diferencia y variación”. El texto de Santillán enmarcado en esta perspectiva teórica "propicia la complejidad y la multiplicidad interna", por el hecho de sorprender a través de las contradicciones temporales y espaciales desafíando la lógica de los modelos canónicos.

No obstante, las relaciones entre los textos son "saludables" en lo que respecta al resultado final y es ese resultado el que se analizará a lo largo de la comunicación; particularmente los intersticios intertextuales que se producen entre la trama mítica y su representación contemporánea, a fin de comprobar que el mito sacraliza el espacio dramático, recuperando las potencias y los saberes humanos al transformar "lo invisible en visible".

\section{Puede que sea resumen lo de arriba}

Como puede leerse en el resumen de la presente comunicación, el dramaturgo tucumano Guillermo Montilla Santillán se apropia una vez más del mito clásico ${ }^{2}$ con la finalidad de instalar en el contexto argentino y latinoamericano la permanencia de las matrices míticas ${ }^{3}$. Así como en otra obra del mismo autor, El jardin de piedra ${ }^{4}$, donde el universo minoico se

${ }^{2}$ Obsérvese la reflexión de N. Fry, en El gran código. Barcelona, Gedisa, 1988, p. 62, sobre el mito: "La mitología no es un datum sino un factum de la existencia humana: pertenece al mundo de la cultura y civilización que el hombre creó y que aún sigue habitando”.

${ }^{3}$ Kusch, R., Pozo de América, en Obras Completas IV, Rosario, Editorial Fundación Ross, pp. 9-10. El autor clasifica los mitos, especialmente, americanos en tres tipos: creación, caída y redeción o escatológicos. El de creación da elementos para entender el modo del domicilio existencial. El de caída que marcaría la distancia teológica entre el sujeto y lo absoluto. Finalmente, el que aquí nos concierne, el de redención que fijaría la culminación de un proceso de hybris o inmersión de la existencia en lo negativo que atraviesa el mito.

${ }^{4}$ Cf. Pégolo, L. - Cardigni, J. - Meardi, F. - Ramírez, C. - Romero, U., "De Teseos y Minotauros: El jardín de piedra de Guillermo Montilla Santillán”, en: López, A. - Pociña, A. (eds.), En recuerdo de Beatriz Rabaza. Comedias, tragedias y leyendas grecorromanas en el teatro del siglo XX, Granada, Universidad de Granada, 2009, pp. 479-489. 
entrecruza con el ingenio zafrero, Silencio de piedra está construido a partir del ciclo troyano, constituyéndose este como un sustrato sugerente de los conflictos eternos del hombre que pugna por la conservación de su identidad ${ }^{5}$.

Es evidente, al confrontar los títulos de la producción de Montilla Santillán, que la piedra ocupa un lugar de privilegio en el imaginario teatral, sobre todo porque el término adquiere un valor polisémico: en el primero, sugiere el ámbito aparentemente inexpugnable del laberinto-fortaleza del “jardín”; en el segundo, es el espacio mudo, incorruptible y referencial de las culturas en peligro de expoliación frente al avance extranjero. La pirca diaguita, construida de piedra, sirve de límite contenedor para la casa-corral que, en este caso particular, se convierte en la muralla aborigen, signo-eje dentro de un sistema de signos más amplio que incluye particularmente a la palabra. Esta no se limita al texto propiamente dicho, sino que el epígrafe, una copla perteneciente al poeta y cantor popular Atahualpa Yupanqui, reflexiona sobre el destino del hombre que debe abrirse camino entre la dureza de la piedra, de manera semejante a los ríos que heraclíteamente se oponen a ella y la transforman ${ }^{6}$.

La presencia física y arquitectural de la pirca, que remite al modelo comunitario pre-hispánico, se transforma a través de la acotación autoral ${ }^{7}$, en un denotatum o signo existencial ${ }^{8}$, en la medida en que sus defensores detentan la "piedra" como apellido; asimismo al revisar el conjunto completo de las personae dramáticas se visualiza la presencia del mito clásico con el que la historia dramatizada se entretejerá, estableciéndose una serie de relaciones intertextuales que se estrecharán y alejarán a lo largo del texto ${ }^{9}$.

${ }^{5}$ Silencio de Piedra no está editado en libro. El texto nos fue cedido por el autor en formato digital, y lleva como fecha final de composición el 11 de febrero de 2009. Señalemos que esta obra no es una "reescritura" o "adaptación" de ninguna tragedia clásica: los personajes de Montilla Santillán y sus acciones traducen en un relato autónomo los elementos presentes en el mito troyano, reconocibles, pero a la vez sin depender de manera ancilar de éste. El mito es aquí un sustrato más en los niveles simbólicos del texto. Por otra parte, de acuerdo con las concepciones actuales de escritura dramatúrgica, Silencio de Piedra consiste en un "texto dramático preescénico de primer grado". Seguimos la clasificación propuesta por Dubatti: "Una clase de texto literario dotada de virtualidad escénica, escrito a priori, antes e independientemente de la escena, que guarda un vínculo transitivo con la "puesta en escena." Dubatti,J, Cartografía teatral, Buenos Aires, Atuel, 2008, p. 137.

${ }^{6}$ Yupanqui, A., "Pasar la vida entre piedras, / Nuestro destino / Pasar la vida entre piedras / Como los ríos."

7 "Interior de una casa cercada de pircas, en las montañas Diaguitas del Norte Argentino."

${ }^{8}$ Eco, U., en La estructura ausente. Introducción a la semiótica. Barcelona, Lumen, 1989, pp. 285 ss., toma las consideraciones de G. Klaus Koenig, sobre la semiótica de Morris, para elaborar el concepto de denotata del signo arquitectónico.

${ }^{9}$ Entre los personajes que denotan una significación mítica se encuentran Héctor, del que se recuerda su condición de "domador de caballos", y la bella Helena, protagonistas del conflicto de la estirpe de los Piedra; asimismo aparecen otros que, como Facundo, está privilegiado con 
$\mathrm{Y}$ es precisamente esta dialéctica de las referencias textuales, entre Troya y la soledad pre-cordillerana, la que motivó nuestro interés sobre Silencio de piedra, pues advertimos que el texto impone, siguiendo a J. Dubatti, "espacios de heterogeneidad, tensión, debate, cruce, e hibridez de diferentes materiales y procedimientos, espacios de diferencia y variación" que instan al análisis. El texto de Montilla Santillán, enmarcado en la perspectiva teórica de las poéticas teatrales y de la literatura comparada, "propicia la complejidad y la multiplicidad interna"10, por el hecho de sorprender a través de las anacronías temporales y las diferencias espaciales, desafíando, en particular, la lógica de los modelos canónicos.

La primera "contradicción" -que es solo aparente- se advierte en otro elemento paratextual como es la dedicatoria; en ella el autor evoca a su abuelo sobre el cual destaca su condición gauchesca de pialador; a esta se agrega metafóricamente el hecho de "pialar" o atar sueños, tarea esta no diferente a la de contar historias ${ }^{11}$, como lo suelen hacer los abuelos hacia sus nietos, sosteniendo la transmisión oral de los relatos que constituyen la identidad de los pueblos en el hecho de "atarlos" a los orígenes y las causas. Frente a la evocación, la donación del texto a través del cual el autor asume, metatextualmente, su labor de narrador en el presente que vigila para asirse al pasado legendario, especularmente reflejado en el presente:

A Don Laurindo Santillán Sal, pialador de sueños, contador de historias, hombre de bien y abuelo.

Para vos, Tata, que me contaste tantas historias para conciliar el sueño, para soñar en la vigilia. Ahora me toca a $\mathrm{mi}^{12}$.

¿Cuál es la historia que el autor "contará" dramatizada? Aquella que se debatió frente a las murallas de Troya y la que las tradiciones post-homéricas transmitieron sobre la destrucción de la ciudad, a partir de la noche fatídica en la que el caballo de madera, abandonado ante sus curiosos habitantes en

la carga semántica de portar el nombre de uno de los héroes más controvertidos de la historia argentina del XIX. En el caso de Bórquez, remite al apellido de un militar chileno que participó en la pacificación de la Araucanía y fue destinado, hacia finales del 1800, a luchar en la zona de la Puna de Atacama. Están también personajes de los que se habla de manera narrativizada, como los Guanco, representados por el número tres, y una referencia sumamente importante de la figura de Aquiles al que no se nombra y Bórquez dice de él que "hay uno entre ellos, un gringo de crines bayas y ojos brillantes que de sólo mirar mete miedo. Y hay rumores sobre él [...] Qué es mitad diablo. Que le rebotan las balas como si tuviese la piel de hierro".

${ }^{10}$ Dubatti, J., Concepciones de teatro. Poéticas teatrales y bases epistemologías, Buenos Aires, Colihue, 2009.

${ }^{11}$ Bettelheim, B., en Psicoanálisis de los cuentos de hadas, México, Grijalbo, 1988, p. 53, afirma lo siguiente con respecto a la semejanza entre los mitos y los cuentos de hadas, ya que ambos "nos hablan en el lenguaje de los símbolos, representando el contenido inconsciente".

${ }^{12} \mathrm{El}$ autor utiliza la cursiva en la dedicatoria. 
la playa, ("sólo el potro gigantesco se alzaba como quien quiere alcanzar el cielo"), dio muestra del ardid de los que serían los vencedores. Con el recurso de la metáfora y del oxímoron, la voz de Alcira, que representa a la maldecida Casandra, se alza para dar a conocer vaticinios prodigiosos, aún no cumplidos ("Vivo por dentro, muerto por fuera, aguardando ser llevado detrás del muro de piedra, para trocarlo todo en cenizas.").

El temor que se agiganta en la oscuridad de la noche hace que los hermanos Piedra (Héctor, el mayor; Facundo, el más resuelto a devolver a Helena, a la que no se nombra, y Juan, que teme por la endeblez del adobe, en consecuencia de las defensas) discutan por la decisión a tomar. Se encuentran en la encrucijada trágica que ya está establecida de antemano: ¿cuál es el precio que se debe pagar por el amor de una mujer? ¿Vale este el desapegarse de la tierra? ¿O debe cumplirse el sacrificio expiatorio que se le exige al héroe? ${ }^{13}$ Así habla Héctor:

"Héctor: Aquí, detrás de las pircas y el adobe nos defenderemos.

$[\ldots]$

Facundo: Héctor, hermano, de rodillas te lo imploro, por el bien de todos, entregála.

Héctor: De pie, hermano, de pie. La noche no es apta para decidir caminos. Dejemos que la jornada nos alcance.

$[\ldots]$

Héctor: Mi amor es tierra. Maldito sea mil veces si no hiciera lo mismo por cualquiera de ustedes. Maldito sea."

Los conceptos de Benjamin recordados por Szondi nos permiten reflexionar sobre la intención de Montilla de recrear el modelo trágico, principalmente en lo que respecta a su significación simbólica: en el ejemplo anterior se percibe una nueva oposición: la del sometimiento a la tierra como sostén de la ley antigua y la necesidad de salvación del pueblo a través de su violación. El héroe se enfrenta a las decisiones personales e individualistas (la de sus hermanos, incluso la de Jerónimo, un Paris enamorado, que aún no ha aparecido en escena) para fundar una ley nueva que acabará con su existencia para permanecer en la palabra de una comunidad distante ${ }^{14}$.

De lo expuesto hasta aquí pueden desprenderse dos direcciones de análisis: por un lado resulta significativo interpretar Silencio de Piedra como

${ }^{13}$ Szondi, P., en Teoría del drama moderno. Tentativa sobre lo trágico, Barcelona, Ensayos / Destino, 1994, p. 230, recuerda la posición de W. Benjamin sobre la tragedia ática frente al drama barroco: La poesía trágica descansa en la idea del sacrificio. Pero el sacrificio trágico se diferencia de cualquier otro por su objeto (el héroe) y constituye al mismo tiempo un comienzo y un final. Un final porque es un sacrificio expiatorio debido a los dioses, guardianes de la ley antigua; un principio porque se trata de una acción sustitutiva en la que se anuncian nuevos contenidos de la vida del pueblo.

${ }^{14}$ Ibid., p. 231. 
una manifestación muy personal de la poética simbolista surgida en Europa a fines del siglo XIX, con evidentes proyecciones a lo largo del siglo XX y en la actualidad. ${ }^{15}$ Por otro, las concepciones de tierra y mundo mítico imbricadas en esta obra reclaman que no dejemos de lado la fuerza territorial que genera el teatro como experiencia convivial: la pirca no es un elemento simplemente referencial ni mucho menos de "color local" sino un organizador de la experiencia de interpretación semántica, tal como desarrollamos a continuación.

Con respecto a la poética del drama simbolista, resulta esclarecedor recordar los seis niveles de construcción simbolista propuestos por Dubatti:

- Simbolismo sensorial: la imagen escénica apela a lo extracotidiano por varias vías; en el caso de Silencio de Piedra, esto se advierte en el recurso musical (el "lejano golpe de bombos y tambores", indicado en una acotación final, está en correlación con el último parlamento de la obra: "Que hagan callar a las piedras, si es que pueden." Y con el silencio que cierra la obra: "Abrupto silencio."), en las voces de los muertos (que son "sombras esfumadas, salidas de la nada"), en el manejo de la luz velada. (Se verá que la "oscuridad" indicada en las acotaciones es un correlato del "silencio".)

- Simbolismo narrativo: la obra maneja una temporalidad que produce enlaces lógicos y causales imposibles de ser entendidos de un modo "objetivo" o exterior. Varias acotaciones indican: "Días antes”, "presente”, "mediodía”, "noche", "días después", "meses después". Se evita la linealidad expositiva racionalista y la gradación de conflictos.

- Simbolismo referencial: se intenta crear enlaces entre lo visible y lo invisible, lo presente solo a nivel metafísico, maravilloso o ancestral. La presencia de los sueños como presagio o índice de lo terrible es recurrente:

"Alcira: Soñé con un caballo. Un caballo de piedra. [...] Escuché al viento soplando entre sus patas, silbando entre las lajas que dibujaban sus crines. Parecía un tributo, pago a la tierra por tanto daño, por tanta sangre. Parecía muerto. Pero por dentro latía”16.

${ }^{15}$ El movimiento simbolista opera en la idea de que el mundo exterior registrado por nuestros sentidos no es la realidad última sino solo el reflejo de un ámbito de revelaciones absolutas que permanece oculto. Esta realidad auténtica puede evocarse por distintos recursos simbólicos. Tal como afirma Jaime Rest: "El empleo de procedimientos simbólicos ha sido característico de la literatura en todas las épocas, pero la denominación simbolismo suele emplearse en forma específica para designar un movimiento poético que se originó en Francia en las postrimerías del siglo XIX y que tuvo honda y decisiva gravitación en el desenvolvimiento de las experiencias vanguardistas de diversas lenguas". Cf. Rest, J., Conceptos fundamentales de la literatura moderna, Buenos Aires, CEAL, 1979, p. 145.

${ }^{16}$ Más adelante Alcira anticipará el destino final de los defensores al afirmar: "Vendrán por miles, no por cientos y serán tantos que el horizonte quedará oculto detrás de sus sombras. Como las langostas en los sembradíos lo consumirán todo. ¡Ay! Héctor, si pudieras verlo ahora. $\mathrm{Si}$ pudieras ver como yo antes de que el tiempo llegue. Correrá la sangre hasta enrojecer los 
La referencia al caballo de Troya no es un gesto erudito y vacío, sino que subraya la presencia de las fuerzas míticas como realidades profundas, telúricas: se trata de un caballo de piedra, como las pircas y la tierra que rodea todo.

- Simbolismo lingüistico: Basado en la belleza y fuerza alusiva de las palabras, vistas no como un enlace directo con la realidad, sino muchas veces en relación a lo inefable. (Recordemos el título de la obra y la indicación de silencio final.) Como hemos dicho, la obra se abre con la voz de Alcira, la adivina:

"El prodigio fue simple. Adormecidas y solas sobre largas extensiones de arena las tiendas cantaban con el viento. En el silencio que a gritos despuntaba con el alba, sólo el potro gigantesco se alzaba [...] Forjado en la madera arcana de los escudos y las picas".

En Silencio de Piedra no solo hay un desarrollo buscado de lo metafórico sino que se encuentran pasajes líricos que necesitan una modalización eminentemente "artística", es decir, autónoma, no realista.

- Simbolismo semántico: el teatro simbolista es concebido como un jeroglífico; se construye un símbolo (que puede ser un personaje, un objeto o un espacio) integrado en una situación dramática que no "expone" una tesis como en el drama realista sino que estimula al espectador a que perciba lo desconocido. En el caso de Silencio de Piedra, es evidente que el símbolo es el espacio: la tierra y la piedra son esencias últimas de realidad solo comprensibles en su silencio elocuente. Los personajes se movilizan en defensa de la tierra ante "los gringos" y sus ofertas monetarias, o ante el gobierno con sus falsas promesas de no tocar el agua para llegar a la mina. En este asedio, es el adobe el que tiene que resistir, porque un hombre sin tierra no es nada. Y es precisamente Héctor quien afirma: "Prefiero morir en mi tierra que vivir sin ella".

Simbolismovoluntario: se trata de un tipo de teatro basado en la complicidad del espectador para acceder a los sentidos desplegados por la obra. Recordamos nuevamente con Dubatti que en la concepción de mundo simbolista operan "la recuperación de potencias y saberes humanos perdidos o por desaparecer: el misterio, la magia, la visión, la fascinación por las formas de lo desconocido más allá de los límites de la materia y de la razón"17.

Pero también hablábamos antes de la fuerza territorial del teatro. Consideramos que Silencio de Piedra no construye sus sentidos en la intertextualidad literaria sino en un procedimiento que podríamos llamar inter-territorialidad. No es el peso de las alusiones clásicas lo que estructura la

ríos. La muerte beberá aún después de estar saciada, se llevará a todos. A los más bravos y a los cobardes. A todos".

${ }^{17}$ Dubatti, J., idem nota 8, pág. 152. 
obra sino las relaciones que se generan entre el espacio de la escena y el mito clásico entendido como territorio suprahistórico; pero también, y de un modo más fuerte, entre el territorio de los personajes y su contexto inmediato: la tierra misma donde se desarrolla la obra, donde ha sido creada, donde vive el público que traduce y produce los símbolos. La defensa de la tierra es también la defensa de una poética particular, local por naturaleza inevitable, pero no "localista". Si como dijimos antes, esta obra puede considerarse un texto preescénico, imaginamos que una puesta en escena del texto deberá indagar de qué modos esa virtualidad teatral presente multiplique en los aspectos no verbales la fuerza simbólica de la escritura poética.

Finalmente, desde la perspectiva de Kusch, lo descrito anteriormente con respecto al simbolismo se puede encuadrar dentro del concepto de cultura que expone el pensador argentino del siguiente modo:

"Cultura no es sólo el acervo espiritual que el grupo brinda a cada uno y que es aportado por la tradición, sino además es el baluarte simbólico en el cual uno se refugia para defender la significación de su existencia. Cultura implica una defensa existencial frente a lo nuevo, porque si careciera uno de ella no tendría elementos para hacer frente a una novedad incomprensible"18.

Específicamente, a partir de esta noción de cultura se puede comprender cabalmente la resignificación del mito aludido a través de la importancia concedida a lo autóctono (las pircas, la tierra, el agua, la doma y las canciones) y su defensa aún a costa de la propia vida ya que aquí se juega el sentido de la misma. Así, la cultura está íntimamente ligada al suelo "que no es ni cosa, ni se toca pero que pesa" ${ }^{19}$ y que además brinda arraigo en los momentos críticos. Piénsese en la canción entonada por los hermanos y recibida de los antepasados cuando esperan la segura muerte. De la combinación de los conceptos de suelo y cultura, el autor propone la necesidad de la geocultura ${ }^{20}$ como la actividad de pensar a partir de los problemas y vivencias latinoamericanas, más allá de la tradición racional occidental. En este sentido, el mito griego renace en el problema actual de la minería y en una comarca donde la tradición se respira en el ambiente y escapa al logocentrismo de Occidente.

${ }_{18}$ Kusch, R., Esbozo de una antropología filosófica americana, Buenos Aires, Ediciones Castañeda, 1978, pp. 13-14.

${ }^{19}$ Kusch, R., Geocultura del hombre americano, en Obras completas III, Rosario, Editorial Fundación Ross, 2000, p. 110.

${ }^{20}$ Kusch, R., idem, 1978, pp. 15-18. 